as an overall process. There is, for example, no mention of amino-acid pools and their relationship to growth.

Overall, therefore, this book is a quite excellent account of the microbial biochemistry and physiology in the rather static form in which it was studied until relatively recently: pathways existed and material flowed along them-but to what precise purpose ? Where end-product inhibition occurred was it really exercised by the endproduct? There is really very little attempt to put the processes described into their context in the architecture of the cell and this makes the book rather drab reading to anyone who finds the investigation of the relationship between structure and function in bacteria-and one hopes that these will include all current students-such an exciting pursuit.

M. H. RICHMOND

\section{RANDOM PROCESSES}

\section{Stochastic Integrals}

By H. P. McKean. (Probability and Mathematical Statisties: a Series of Monographs and Textbooks, No. 5.) Pp. xiii +140 . (Academic Press: New York and London, March 1969.) $84 s$.

THIs little (but unfortunately expensive) book deals with a special, albeit very important, aspect of the mathematical theory of random processes; essentially with the theory of integrals of the form $\int_{0}^{t} e \mathrm{~d} b$, where $b(t)$ is the famous Bachelier-Wiener model of one-dimensional Brownian motion. The price paid for the simplicity of the model is an extreme irregularity of behaviour; the total distance $\int_{0}^{t}|\mathrm{~d} b|$ travelled by the Brownian particle is always infinite, and the definition of the integral is by no means an easy matter. The book is really a hymn to the beautiful theory of $\mathrm{K}$. Ito, who showed how the integral $\int_{0}^{t} e \mathrm{~d} b$ could be defined and manipulated for a large class of integrands $e$, depending both on time $t$ and on the values of $b(s)$ for $s \leqslant t$.

As one expects from Professor McKean, the treatment is elegant and economical; its conciseness can be seen from the fact that he has been able in 140 pages to include rigorous introductions to such topics as the fine structure of the Brownian path, the construction of general diffusions via their stochastic differential equations, the general form of the Cameron-Martin formula, local time, and diffusions on manifolds and (more especially) on Lie groups. Inevitably, this makes more demands on the reader than would a more leisurely treatment, but the author has gone to some lengths to make his exposition readable, with a large measure of suceess. Anyone familiar with the mathematics of random processes will find the book a rewarding introduction to an interesting theory, and the expert will find a good deal which is new and surprising.

J. F. C. KINGMAN

\section{CHEMICAL TOPICS}

\section{Programmes in Organic Chemistry}

By D. R. Hogg. Vol. 4: Electronic Effects and their Application. (Chemical Science Texts.) Pp. 125. (English Universities Press: London, April 1969.) 16s paper.

THIS is the fourth volume in this useful series of programmes in organic chemistry and is the first one to deal specifically with theoretical topics and their applications; it is divided into three main sections covering in turn the classification of reagents, inductive effects, and mesomeric effects. These programmes were originally devised for second year students at the Uni- versity of Aberdeen to help them obtain a really firm grasp of the principles and to give practice in their application to simple structural and experimental problems. There is separate evidence of the programmes' success in this context and, implicitly, of their thorough testing in the process. They could be used with first year students in universities and technical colleges, and also with more advanced sixth form students in schools.

The programmes are linear, but the size of frame and the type of response required are varied to some extent-choosing between alternative statements, inserting a missing word or words in a sentence, completing a structure, and so on-to reduce the repetitiveness that is inherent in this mode of instruction. This is broadly successful in practice, but one cannot help but feel that the brighter student is going to be bored-his mind is going to work noticeably faster than the programmes can be operated. That apart, one can be left in no doubt at all that a student who has successfully negotiated the three programmes will really understand these topics at the elementary level: no small achievement, for all can, and do, easily lead to ambiguity and confusion in the student's mind.

The subject matter of the programmes is the area of chemistry where visual impact and clarity of representation are particularly important; it is a pity, therefore, to have to say that the reproduction of individual formulae is not nearly as good as it might be, and the pattern of arrangement of several formulae with respect to each other in a reaction scheme often leaves something to be desired, little endeavour being made to focus attention on the salient event that is taking place. That apart, teachers of chemistry will find these programmes useful as an initial source of information for all but the brighter students, and as helpful revision material for them as well.

PeTer SyKes

\section{DESCRIPTIVE GEOLOGY}

\section{The Geological History of the British Isles}

By George M. Bennison and Alan E. Wright. Pp. $\mathrm{x}+406$. (Arnold: London, March 1969.) 100s boards; $50 s$ paper.

Geologrcax history is worked out using the methods of stratigraphy to interpret and synthesize numerous local rock sequences. This poses a dilemma for any writer on geological history: either he expounds his conclusions but skates briefly over the facts and can be accused of failing to give chapter and verse for his interpretation, or he retails the facts at length and can be charged with being unreadable. The present authors have chosen the second course. Notwithstanding the title this book consists largely of stratigraphical description.

The introduction deals briefly with matters such as sedimentation, palaeogeography, fossils and stratigraphical correlation. Stratigraphical principles are not very clearly expounded, and the distinction between lithostratigraphical units and biostratigraphical (or chronostratigraphical) ones is not made perfectly clear. There are a number of careless or inaccurate statements; for example, most stratigraphers would not regard biostratigraphical and time divisions as synonymous (page 24 ), although the latter may depend on the former. The authors seem to have little awareness either of recent discussion or recent practice. The American Code of Stratigraphic Nomenclature is mentioned in passing, but neither it nor other attempts to bring order into the chaos of stratigraphical practice are expounded or discussed. The text sometimes seems inconsequential or inconsistent: on page 20 is the (misleading) statement that "In general different outcrops of strata of the same geological age will possess the same faunal assemblage", while on page 21 "rocks formed contemporaneously 